\title{
Life-history trade-offs in a generalist digenean from cetaceans: the role of host specificity and environmental factors
}

\author{
Natalia Fraija-Fernández ${ }^{*}$ Mercedes Fernández, Juan A. Raga and Francisco J. Aznar
}

\begin{abstract}
Background: Adults and larvae of generalist parasites are exposed to diverse hosts and local environmental conditions throughout their life cycles, thus local adaptation is expected to occur through phenotypic plasticity and/or natural selection. We investigated how the combined effect of cryptic host specificity and local selective pressures could shape reproductive traits of a putative generalist parasite in the oceanic realm.

Methods: The LSU rDNA, ITS2 and the mt-COI of individuals of the digenean Pholeter gastrophilus (Kossack, 1910) Odhner, 1914 (Heterophyidae Leiper, 1909) from oceanic striped dolphins, Stenella coeruleoalba Meyen, and coastal bottlenose dolphins, Tursiops truncatus Montagu, in the western Mediterranean were used to elucidate whether worms were conspecific. Infection parameters were compared between both dolphin species. General Linear Mixed Models were used to analyse the influence of host species on four reproductive traits of $P$. gastrophilus: body size, maturity stage (non-gravid/gravid), egg size, and number of eggs in utero. AIC values were used to rank competing models, and $p$-values to assess the effect of specific predictors.
\end{abstract}

Results: Evidence indicated that worms collected from both dolphin species were conspecific. All worms collected were gravid and infection parameters did not differ between dolphin species. However, body size and egg size of individuals of $P$. gastrophilus were significantly larger in striped dolphins. The number of eggs in utero did not significantly differ between dolphin species but, for a given body size, worms in bottlenose dolphins harboured more eggs. A trade-off between egg size and egg number was found in worms from both dolphin species, with a higher slope in striped dolphins.

Conclusions: Apparently, striped dolphin is a more suitable host for $P$. gastrophilus, but reproductive investment seems to be adapted to the habitat where the life-cycle develops. Worms from striped dolphins likely face the problem of finding intermediate hosts in the oceanic realm and apparently invest into offspring size to enhance the early survival of larvae and the potential to multiply asexually within the first intermediate host. The small-sized worms from bottlenose dolphins would be adapted to reproduce early because of higher adult mortality, generating smaller and numerous eggs in a coastal habitat where chances of transmission are presumably higher.

Keywords: Host specificity, Trade-off, Egg size, Fecundity, Digenea

\footnotetext{
* Correspondence: natalia.fraija@uv.es

Marine Zoology Unit, Cavanilles Institute of Biodiversity and Evolutionary

Biology, Science Park, University of Valencia, PO Box 22085, 46071 Valencia,

Spain
} 


\section{Background}

Host specificity is a measure of the degree to which parasites species can exploit different host species. Differences of specificity are a matter of degree rather than kind: at one extreme, specialist parasites can exploit only one or very few host species; at the other extreme, generalist parasites can infect and reproduce in a number of host species [1]. According to the encounter/compatibility paradigm, the degree of specificity of any parasite is determined by the action of two sequential filters. The 'encounter' filter prevents infections of potential hosts that cannot contact the parasite, whereas the 'compatibility' filter excludes contacted hosts in which the parasite cannot find the appropriate resources and/or escape or deter the host's defenses [2, 3]. If the contacted hosts are suitable but suboptimal, the compatibility filter can still negatively affect fitness components of the parasite.

A fundamental question regarding host specificity is the extent to which a putative generalist parasite performs equally well in all exploited host species, namely, whether these hosts are all equally compatible for the parasite [4]. This question has important implications, not only for understanding the evolution of specificity, but also for population dynamics and epidemiology of generalist parasites [5]. In some cases, there is little evidence that sympatric hosts impact differently the performance of a putative generalist parasite, e.g. [5]. Other studies, however, have reported on significant host species effects on fitness-related traits of the parasite such as dwarfism and impaired reproduction in presumably suboptimal hosts, e.g. [6-8]. Other studies have discovered more subtle effects on parasite's life history traits (e.g. fecundity) of host species that, at first glance, seemed to be equally suitable for the parasite, e.g., [9-11]. It should be stressed, however, that some putative generalist parasites have later been re-interpreted, based on molecular evidence, as cryptic species complexes, each species being adapted to a different host $[12,13]$.

Differences of performance of a generalist parasite among host species usually result from the diverse conditions each host species provides $[14,15]$. For instance, a parasite can be adapted to some host species, but is also able to reproduce, with reduced success, in related hosts because, in the latter, the parasite suffers a shortage of trophic resources or harsh physiological conditions, or incur higher costs in the face of host immune responses [16, 17]. However, individual life history traits are constrained, not only by phylogenetic, physical or developmental factors, but also by trade-offs with other traits [18]. Selection pressures operate on the whole lifecycle and, therefore, trade-offs are optimised for the specific environment where the life-cycle develops [19-21]. Therefore, it is important to consider not only the microhabitat conditions each host species provides, but also where each host lives. To our knowledge, few studies have analysed how the combined effect of host species constraints, and local selective pressures on the life-cycle, could shape life history traits of a generalist parasite, e.g. [5].

In this paper, we investigate this issue in a digenean infecting two cetacean species that occur in different habitats, i.e. coastal and oceanic. Pholeter gastrophilus (Kossack, 1910) Odhner, 1914 is a member of the family Heterophyidae Leiper, 1909 that has been reported as adult in at least 17 odontocete species inhabiting coastal, oceanic and even freshwater habitats worldwide [22]. Worms live encysted inside fibrotic nodules in the wall of glandular chambers of the stomach [23]. Eggs are released to the stomach lumen through a narrow duct that stems from the cyst $[24,25]$. The life-cycle of $P$. gastrophilus is not known but, based on the broad ecological distribution of its definitive hosts and evidence on the life-cycles of other heterophyids, it can be postulated that molluscs act as first intermediate hosts, and a wide array of invertebrates and/or fish are second intermediate hosts $[23,25]$.

In the western Mediterranean, P. gastrophilus has been reported in four sympatric cetacean species, i.e. the Risso's dolphin, Grampus griseus G. Cuvier, the long-finned pilot whale, Globicephala melas Traill and, especially, the bottlenose dolphin, Tursiops truncatus Montagu, and the striped dolphin, Stenella coeruleoalba Meyen [26-30]. Gravid specimens of $P$. gastrophilus have been found in all these host species, but a more rigorous analysis, of the extent to which host species may affect growth and reproduction of the parasite, has never been carried out. Interestingly, the Mediterranean hosts of P. gastrophilus live in ecologically distinct habitats. In particular, striped dolphins, Risso's dolphin and long-finned pilot whales are primarily oceanic species, whereas bottlenose dolphins favour more coastal waters $[31,32]$. The extent to which environmental factors associated to oceanic vs. coastal realm also influence the reproductive strategies of $P$. gastrophilus is an open, interesting question.

In this study, we examined patterns of host specificity of P. gastrophilus collected from bottlenose and striped dolphins in the western Mediterranean with four specific aims. First, we ascertained if worms collected from both host species belong to a single generalist taxon or represent a species complex. Second, we compared infection parameters of P. gastrophilus between both dolphin species. Third, we analysed host-parasite compatibility based on a comparison of four reproduction-related traits, i.e. body size, presence/absence of eggs, number of eggs in utero, and egg size. Finally, we explored whether a phenotypic trade-off between egg number and egg size occurred [33-35], and whether it was optimised differently for each host species. We acknowledge from the outset that the amount of data that can be gathered from this system is limited. However, 
the results obtained strongly suggest how host suitability and environmental conditions can modulate some key features of the life history strategy of an oceanic parasite.

\section{Ethical approval}

Permission and funding to collect stranded dolphins was given by the Wildlife Service of the Valencian Regional Government, Spain, which is the official institution in charge of managing and protecting wildlife in the region. No ethics board was involved because animals were collected after their natural death.

\section{Methods}

\section{Sample collection}

A total of 39 striped dolphins and 21 bottlenose dolphins stranded on the Mediterranean coast of Spain $\left(40^{\circ}\right.$ $25^{\prime} \mathrm{N}, 0^{\circ} 26^{\prime} \mathrm{E}$ and $37^{\circ} 58^{\prime} \mathrm{N}, 0^{\circ} 41^{\prime} \mathrm{W}$ ) were collected during 1990-2005. Only well-preserved carcasses (state 1-3 sensu [36]) were selected for analysis. Animals were brought to the laboratory and immediately necropsied; the stomach was removed and frozen at $-20{ }^{\circ} \mathrm{C}$ for later examination. After thawing, each stomach chamber was examined separately for the presence of $P$. gastrophilus. Nodules were detected through visual and tactile screening and incisions were made on each nodule to confirm the presence of $P$. gastrophilus. When positive, the nodule was removed and carefully cut into slices to collect and count all worms. Finally, the stomach content was filtered over a sieve with $0.02 \mathrm{~mm}$ mesh spacing to collect worms that were free in the lumen. Specimens of P. gastrophilus were washed in $0.9 \%$ saline and fixed in absolute ethanol for molecular analysis or $70 \%$ ethanol for morphometric analysis.

\section{Molecular analyses}

Single individuals of $P$. gastrophilus collected from five bottlenose dolphins, and six worms collected from five striped dolphins were used for molecular analysis to elucidate whether all worms were conspecific. Genomic DNA was extracted from individual worms using a standard phenol-chloroform protocol. Partial large subunit (LSU) rDNA was amplified in two specimens of $P$. gastrophilus from each dolphin species using primers LSU5 [37] and LSU1500R [38]. The ITS2 rDNA was amplified in four worms from each dolphin species using primers 3S [39] and ITS2.2 [40]. The mitochondrial COI was amplified from five and three worms from striped and bottlenose dolphins, respectively, using primers JB3 [41] and JB4.5 [42]. An additional primer, $300 \mathrm{~F}$ [43] was used as an internal primer for sequencing the LSU rDNA. Thermocycling profiles for gene amplification were as follows: for the LSU rDNA, initial denaturation at $94{ }^{\circ} \mathrm{C}$ for $3 \mathrm{~min}, 40$ cycles of $94{ }^{\circ} \mathrm{C}$ for $30 \mathrm{~s}, 56{ }^{\circ} \mathrm{C}$ for $30 \mathrm{~s}, 72{ }^{\circ} \mathrm{C}$ for $2 \mathrm{~min}$, and a final extension at $72{ }^{\circ} \mathrm{C}$ for
7 min [38]; for the ITS2 rDNA, initial denaturation at $95{ }^{\circ} \mathrm{C}$ for $3 \mathrm{~min}, 40$ cycles of $94{ }^{\circ} \mathrm{C}$ for $50 \mathrm{~s}, 56{ }^{\circ} \mathrm{C}$ for $50 \mathrm{~s}, 72{ }^{\circ} \mathrm{C}$ for $80 \mathrm{~s}$, and a final extension at $72{ }^{\circ} \mathrm{C}$ for $4 \mathrm{~min}$ [13]; and for the mitochondrial COI gene, initial denaturation at $94{ }^{\circ} \mathrm{C}$ for $5 \mathrm{~min}, 40$ cycles of $92{ }^{\circ} \mathrm{C}$ for $30 \mathrm{~s}, 45.6{ }^{\circ} \mathrm{C}$ for $45 \mathrm{~s}, 72^{\circ}$ for $90 \mathrm{~s}$, and a final extension at $72{ }^{\circ} \mathrm{C}$ for $10 \mathrm{~min}$ [42]. Amplicons were purified with a GFX PCR DNA and Gel Band Purifying Kit (GE Healthcare Life Sciences, Buckinghamshire, UK) and cycle sequenced on an Applied Biosystems 3730 DNA Analyser, using Big Dye version 1.1. Contiguous sequences were assembled and analysed using BioEdit v.7.0.5.3 [44]. Sequences are available online in the GenBank with accession numbers as follows: sequences for P. gastrophilus from striped dolphins [KT883852 (LSU rDNA); KT883854 (ITS2 rDNA); KT883856 (mt COI)] and sequences of $P$. gastrophilus from bottlenose dolphins [KT883853 (LSU rDNA); KT883855 (ITS2 rDNA); KT883857 (mt COI).

\section{Comparison of infection parameters}

The $95 \%$ confidence intervals (CI) for prevalence of $P$. gastrophilus in striped and bottlenose dolphins was calculated with Sterne's exact method [45], and for mean values of intensity, with the bias-corrected and accelerated bootstrap method using 20,000 replications [46]. Prevalence was compared between both dolphin species with Fisher's exact test and mean intensity with bootstrap t-tests [46]. Also, a Brunner-Munzel test was used to compare the probability that the intensity of $P$. gastrophilus in individual hosts from one dolphin species was higher than that in individual hosts from the other dolphin species [47]. These analyses were carried out with the free software Quantitative Parasitology v. 3 [46].

\section{Comparison of life-history traits}

Individuals of $P$. gastrophilus collected from five freshly dead striped dolphins ( $n=140$ worms) and five bottlenose dolphins $(n=97)$ were used for comparison of four reproductive traits: body size, maturity stage (gravid/nongravid), egg size, and number of eggs in utero. Parasites were stained with iron acetocarmine; excess of carmine was removed with $\mathrm{HCl}$ in $70 \%$ ethanol. Specimens were dehydrated through a graded ethanol series, cleared with dimethyl phthalate and mounted as permanent preparations in Canada balsam. Body area and uterine area filled with eggs were drawn for each individual using a stereomicroscope $(\times 40)$ connected to a drawing tube. In platyhelminths, areas provide a good proxy of body size and the size of irregular elements $[8,48,49]$. Empty portions of the uterus could not be observed because the uterine wall is very faint and frequently obscured by vitelline follicles. The area of 10 randomly selected eggs were also drawn using a light microscope $(\times 200)$ connected to a 
drawing tube (Fig. 1). A single value of egg area per worm was obtained by averaging measurements from 10 eggs. Egg areas were preferred over egg volumes (calculated assuming regular shapes) for consistency with the other measurements. All areas were calculated with the program Image Tool v.3.0 [50]. The number of eggs in utero was calculated by dividing the uterine area filled with eggs by the average egg area for each parasite. We confirmed that this method was a good proxy for the number of eggs in utero as follows. After calculating the number of eggs in utero as described above, we de-mounted 10 randomly chosen worms from striped dolphins $(2$ per individual host) and 10 from bottlenose dolphins ( 2 per individual host). Each worm was torn apart in $2000 \mu \mathrm{l}$ of saline to release all eggs. The solution was homogenised with a magnetic stirrer and eggs from 3 samples of $20 \mu \mathrm{l}$ were counted with the aid of a Bürker chamber following the manufacturer's recommendations (OptikLabor, Lancing, UK). The average of the three counts was used as a measure of the number of eggs per $\mu$ l. The relationship between the number of eggs in utero calculated with the two methods was linear, fairly strong and highly significant (Pearson's correlation, $r=0.67, p=0.001$ ).

General Linear Mixed Models (GLMMs) with type III sum of squares were used to analyse the influence of different predictors on body area, number of eggs in utero and egg area of P. gastrophilus [51]. Morphometric variables were $\log 10$-transformed prior to analysis. We used the values of Akaike Information Criteria (AIC) to rank competing models with different numbers of fixed and random parameters. The model with minimum AIC was considered the "best model", and the rest of the models were ranked according to differences in their AIC values [52]. Models with values of $\triangle \mathrm{AIC} \leq 2$ were considered to have substantial empirical support, whereas those having $\triangle \mathrm{AIC}>4$ were assumed to have much less support [53]. It was also assumed that models with Akaike weights $\left(w_{i}\right) \leq 0.01$ were unlikely to be the "true" model [53] and, therefore, they are not shown in the tables. Fixed parameters in all candidate models, excluding the intercept, were also tested for statistical significance using $\mathrm{F}$ - or $\mathrm{t}$-tests.

In models accounting for variability in worm body area, 'host species' (factor),intensity' (covariate), and 'host species"intensity' were considered as potential predictors, i.e. fixed factors. 'Intensity' was included to investigate possible crowding effects on body size [49]. 'Individual host' was considered as a potential random parameter, i.e. a random intercepts model. In models accounting for both variability in number of eggs in utero and egg area, "host species', 'worm body area' (covariate), and 'host species"worm body area' were considered as potential predictors. 'Individual host' and 'worm body area' were considered as potential random parameters. In this case, the random part of the models were allowed to include individual

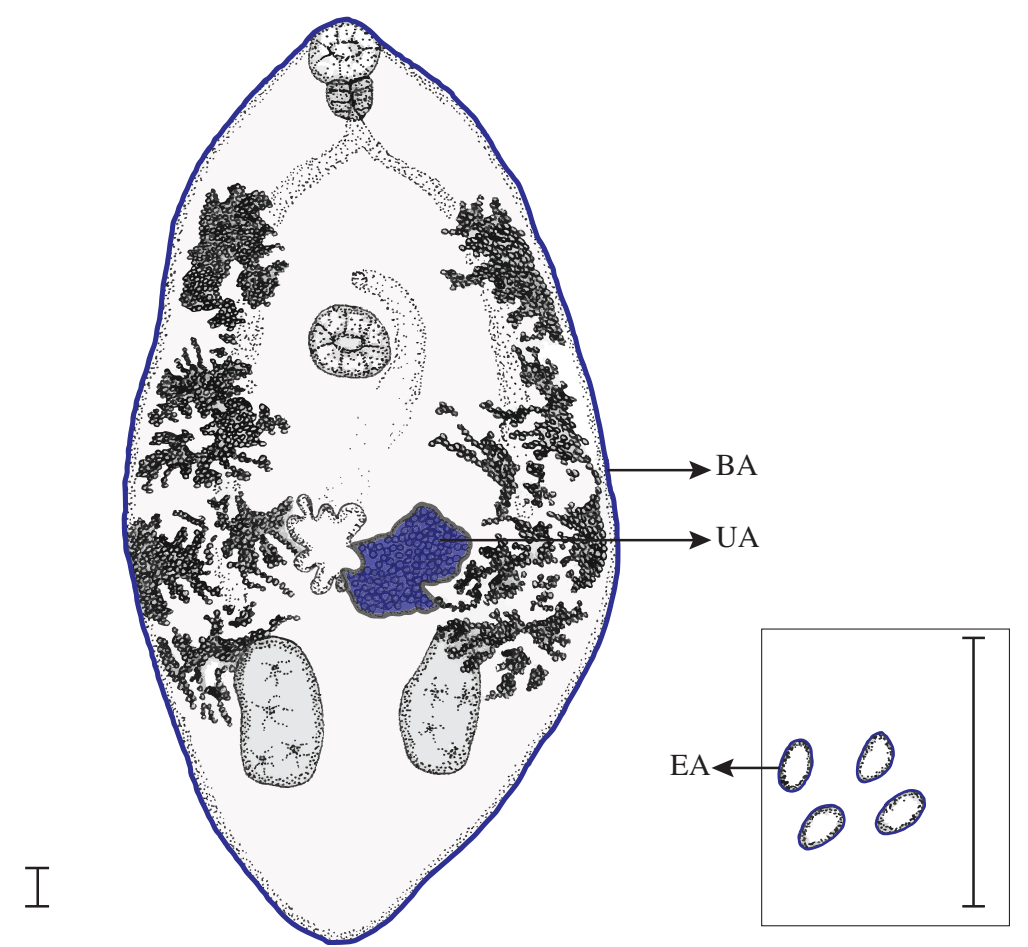

Fig. 1 Schematic drawing of a specimen of Pholeter gastrophilus and its eggs (inset). Colour lines represent measurements taken for the study. Abbreviations: BA, body area; UA, uterine area covered by eggs; EA, egg area. Scale-bars: $0.1 \mathrm{~mm}$ 
host' (i.e. a random intercepts model), 'individual host' + 'worm body area' (i.e. a random intercepts and random slopes model), and 'individual host' + 'worm body area' + covariance between intercepts and slopes (i.e. an unstructured model; see [51]).

The trade-off between egg size and egg number was also assessed through GLMMs. In this case we used Type I sum of squares since we wanted to control for the effect of parasite body area on either number of eggs in utero and egg area [54]. 'Worm body area' (covariate), 'egg area' (covariate), 'host species', 'host species"worm body area' and 'host species*egg area' were entered sequentially in the models as potential predictors. 'Individual host,' 'worm body area' and 'egg area' were considered as potential random parameters. In this case, the random part of the models were allowed to include (i) 'individual host'; (ii) 'individual host' + 'worm body area'; (iii) 'individual host' + 'egg area'; (iv) 'individual host' + 'worm body area' + 'egg area'; and (v) 'individual host' + 'worm body area'+'egg area' + covariance between intercepts and slopes. GLMMs were implemented with SPSS for Macintosh, v. 19.0.

\section{Results}

\section{Molecular analyses}

We obtained four partial LSU rDNA sequences for $P$. gastrophilus (816-1,285 bp long). The eight sequences from each, the ribosomal ITS2 spacer and the mitochondrial COI gene varied between 466 and $515 \mathrm{bp}$, and between 396 and 446 bp, respectively. Comparison of pairwise divergence for each gene showed that the aligned portions of the sequences of all specimens of $P$. gastrophilus were identical.

\section{Infection parameters}

The prevalences $(95 \% \mathrm{CI})$ of $P$. gastrophilus in striped and bottlenose dolphins were $56.4 \%(40.5-71.3)$ and $57.1 \%$ (35.4-76.7), respectively; the difference was not significant (Fisher's test, $p=1$ ). Mean intensity of $P$. gastrophilus also did not differ between both host species: 77.7 (50.7-134.6) worms per infected host in striped dolphins vs. $249.2(82.9-644.4)$ worms per infected host in bottlenose dolphins $(\mathrm{t}=-1.321, p=0.277)$. In addition, the Brunner-Munzel test was not significant $(p=0.847)$.

\section{Comparison of life-history traits}

All individuals of $P$. gastrophilus collected from both, striped dolphins and bottlenose dolphins, were gravid. Mean values of worm body area, number of eggs in utero and egg area are shown in Table 1. The best GLMM for worm body area included only 'host species' and 'host individual' effects; any other model received substantially less empirical support (Table 2). In the subset of models with $w_{i}>0.01$, 'host species' but not 'intensity', was found to be a highly significant predictor of worm body area (Table 2). The average body area of $P$. gastrophilus in striped dolphins was nearly twice that found in bottlenose dolphins, and the difference was consistent regardless of host individual (Table 1).

Table 1 Mean values ( \pm standard deviation, SD) and coefficient of variation (CV in \%) of body area, egg area and number of eggs in utero of individuals of Pholeter gastrophilus collected from five striped dolphins, Stenella coeruleoalba, and five bottlenose dolphins, Tursiops truncatus, stranded along the Mediterranean coast of Spain

\begin{tabular}{|c|c|c|c|c|c|c|c|c|c|}
\hline Host & Intensity & Body area $\left(\mathrm{mm}^{2}\right)$ & CV & Egg area $\left(\mu m^{2}\right)$ & $\mathrm{CV}$ & Egg number & $\mathrm{CV}$ & Uterus area $\left(\mathrm{mm}^{2}\right)$ & $\mathrm{CV}$ \\
\hline \multicolumn{10}{|c|}{ Stenella coeruleoalba } \\
\hline Host 1 & 34 & $3.01 \pm 0.77$ & 25.6 & $227 \pm 46$ & 20.3 & $4,170 \pm 2,391$ & 57.3 & $0.94 \pm 0.53$ & 56.8 \\
\hline Host 2 & 27 & $2.51 \pm 0.42$ & 15.5 & $224 \pm 44$ & 19.5 & $2,148 \pm 2,183$ & 101.6 & $0.43 \pm 0.40$ & 92.8 \\
\hline Host 3 & 35 & $3.63 \pm 0.86$ & 23.6 & $220 \pm 39$ & 17.8 & $5,076 \pm 3,414$ & 67.3 & $1.07 \pm 0.68$ & 63.5 \\
\hline Host 4 & 24 & $4.09 \pm 0.77$ & 18.8 & $204 \pm 30$ & 14.6 & $6,814 \pm 2,945$ & 43.2 & $1.36 \pm 0.57$ & 42.2 \\
\hline Host 5 & 20 & $4.31 \pm 0.86$ & 20.0 & $237 \pm 36$ & 15.0 & $5,984 \pm 1,556$ & 26.0 & $1.43 \pm 0.44$ & 31.0 \\
\hline Total & 140 & $3.44 \pm 0.98$ & 28.4 & $222 \pm 41$ & 18.3 & $4,719 \pm 3,040$ & 64.4 & $1.02 \pm 0.64$ & 62.6 \\
\hline Average per host & 28 & $3.5 \pm 0.75$ & 21.43 & $222 \pm 12$ & 5.4 & $4,838 \pm 1,799$ & 37.2 & $1.05 \pm 0.40$ & 38.1 \\
\hline \multicolumn{10}{|l|}{ Tursiops truncatus } \\
\hline Host 1 & 33 & $2.22 \pm 0.96$ & 43.2 & $233 \pm 39$ & 16.9 & $3,914 \pm 3,068$ & 78.4 & $0.88 \pm 0.68$ & 77.4 \\
\hline Host 2 & 5 & $0.92 \pm 0.33$ & 36.1 & $185 \pm 20$ & 10.6 & $2,125 \pm 879$ & 41.4 & $0.40 \pm 0.18$ & 44.7 \\
\hline Host 3 & 18 & $1.47 \pm 0.23$ & 15.6 & $149 \pm 15$ & 10.4 & $3,209 \pm 1,741$ & 54.2 & $0.48 \pm 0.26$ & 53.0 \\
\hline Host 4 & 19 & $1.27 \pm 0.28$ & 22.0 & $154 \pm 17$ & 11.2 & $1,480 \pm 1,370$ & 92.2 & $0.23 \pm 0.23$ & 96.5 \\
\hline Host 5 & 22 & $2.51 \pm 0.53$ & 21.3 & $169 \pm 26$ & 15.3 & $8,100 \pm 2,168$ & 26.8 & $1.37 \pm 0.40$ & 29.2 \\
\hline Total & 97 & $1.89 \pm 0.82$ & 43.5 & $185 \pm 45$ & 24.4 & $4,164 \pm 3,236$ & 77.7 & $0.77 \pm 0.61$ & 80.2 \\
\hline Average per host & 19.4 & $1.68 \pm 0.66$ & 39.3 & $178 \pm 34$ & 19.1 & $3,765 \pm 2,599$ & 69.0 & $0.67 \pm 0.46$ & 68.7 \\
\hline
\end{tabular}


Table 2 General Linear Mixed Models with type III sum of squares accounting for the effect of host species (factor) and trematode intensity (covariate) on body area of individuals of Pholeter gastrophilus collected from striped and bottlenose dolphins

\begin{tabular}{|c|c|c|c|c|c|c|c|c|}
\hline \multicolumn{3}{|l|}{ Model } & \multirow[t]{2}{*}{$\triangle \mathrm{AlC}$} & \multirow[t]{2}{*}{$w_{i}$} & \multirow[t]{2}{*}{ Predictor } & \multirow[t]{2}{*}{$t$} & \multirow[t]{2}{*}{$d f$} & \multirow[t]{2}{*}{$p$} \\
\hline Fixed effects & Random effects & Covariance structure & & & & & & \\
\hline Intercept + HS & $\mathrm{HI}$ & $\mathrm{Rl}$ & 0.00 & 0.922 & $\mathrm{HS}$ & 3.85 & 7.61 & 0.005 \\
\hline Intercept & $\mathrm{HI}$ & $\mathrm{Rl}$ & 6.39 & 0.038 & - & - & & - \\
\hline \multirow[t]{2}{*}{ Intercept + HS + I } & $\mathrm{HI}$ & $\mathrm{Rl}$ & 6.63 & 0.034 & $\mathrm{HS}$ & 2.84 & 6.80 & 0.026 \\
\hline & & & & & । & 1.38 & 7.31 & 0.209 \\
\hline
\end{tabular}

Models are arranged by increase of Akaike information criterion (AIC) and decrease of Akaike weight $\left(w_{i}\right)$. Models with $w_{i}<0.01$ are not shown. The probability

associated to each fixed effect is also given; significant values are in bold. Abbreviations: HS host species, $H I$ host individual, $R I$ random intercept, $I$ intensity

The best GLMM for the number of eggs in utero included 'host species,' 'worm body area' and the interaction between both variables as fixed predictors, and 'host individual' as a random factor (Table 3). However, three competing models received also substantial support $(\triangle \mathrm{AIC}<4$; $\left.w_{i}>0.10\right)$, and all included both 'host species' and 'worm body area' as fixed factors (Table 3 ). These two factors also were significant predictors in all models $(p \leq 0.015)$, but their interaction was not (Table 3 ). These results indicate that larger worms harboured more eggs regardless of host species and, for a given body size, the number of eggs in utero was significantly higher in worms from bottlenose dolphins (Fig. 2a). Note, however, that in all the models excluding 'worm body area' (all with $\triangle \mathrm{AIC}>4$ ), the effect of 'host species' was not significant $(p>0.05)$. In other words, absolute fecundity was similar between worms from both host species (Fig. 2a).

The best GLMM for egg size included only 'body area' as a fixed, highly significant predictor, and 'host individual' as a random factor (Table 4). Two additional models also received substantial empirical support $\left(\Delta \mathrm{AIC}<4 ; w_{i}>0.10\right)$, and one of them also included 'host species' as an additional predictor (Table 4). The effect of 'body area', but not 'host species', was statistically significant (Table 4). When 'body area' was removed from models, empirical support decreased substantially $(\triangle \mathrm{AIC} \geq 6)$ and the effect of 'host species' was statistically significant $(\mathrm{t}=$ $2.74, \mathrm{df}=8.28, p=0.025)$. Accordingly, the size of the eggs in $P$. gastrophilus increased with worm body size, and the difference of egg size between host species resulted from corresponding differences in worm body size, being larger in striped dolphins (Fig. 2b). This pattern was consistent across host individuals, except in the case of one individual bottlenose dolphin that harboured worms with similar values as those observed in striped dolphins (Table 1).

When evaluating a trade-off between number of eggs in utero and egg area, five models received substantial empirical support ( $\Delta \mathrm{AIC} \leq 2 w_{i}>0.085$ ) (Table 5 ). 'Worm body area' and 'egg area' were included in all models and also received strong statistically significant support $(p \leq 0.005)$. After controlling for body area, a negative relationship was found between the egg number and egg area in all five models (Fig. 3). Parameter for 'egg area' in the best model

Table 3 General Linear Mixed Models with type III sum of squares accounting for the effect of host species (factor) and worm body area (covariate) on the number of eggs in utero of Pholeter gastrophilus collected from striped and bottlenose dolphins

\begin{tabular}{|c|c|c|c|c|c|c|c|c|}
\hline \multicolumn{3}{|l|}{ Model } & \multirow[t]{2}{*}{$\Delta \mathrm{AlC}$} & \multirow[t]{2}{*}{$w_{i}$} & \multirow[t]{2}{*}{ Predictor } & \multirow[t]{2}{*}{$\mathrm{t}$} & \multirow[t]{2}{*}{$d f$} & \multirow[t]{2}{*}{$p$} \\
\hline Fixed effects & Random effects & Covariance structure & & & & & & \\
\hline \multirow[t]{3}{*}{ Intercept + HS + BA + HS*BA } & $\mathrm{HI}$ & $\mathrm{Rl}$ & 0.00 & 0.355 & $\mathrm{HS}$ & -2.58 & 32.68 & 0.015 \\
\hline & & & & & BA & 6.24 & 190.29 & $<0.005$ \\
\hline & & & & & $\mathrm{HS}^{*} \mathrm{BA}$ & 0.64 & 190.29 & 0.526 \\
\hline \multirow[t]{2}{*}{ Intercept $+\mathrm{HS}+\mathrm{BA}$} & $\mathrm{HI}$ & $\mathrm{Rl}$ & 0.07 & 0.342 & $\mathrm{HS}$ & -2.97 & 9.82 & 0.014 \\
\hline & & & & & BA & 9.32 & 189.55 & $<0.005$ \\
\hline \multirow[t]{3}{*}{ Intercept $+\mathrm{HS}+\mathrm{BA}+\mathrm{HS}^{*} \mathrm{BA}$} & $\mathrm{HI}+\mathrm{BA}$ & $\mathrm{RI}+\mathrm{RS}$ & 2.00 & 0.130 & $\mathrm{HS}$ & -2.58 & 32.68 & 0.015 \\
\hline & & & & & $\mathrm{BA}$ & 6.24 & 190.29 & $<0.005$ \\
\hline & & & & & $H S^{*} B A$ & 0.64 & 190.29 & 0.526 \\
\hline \multirow[t]{2}{*}{ Intercept $+\mathrm{HS}+\mathrm{BA}$} & $\mathrm{HI}+\mathrm{BA}$ & $\mathrm{RI}+\mathrm{RS}$ & 2.07 & 0.126 & $\mathrm{HS}$ & -2.97 & 9.82 & 0.014 \\
\hline & & & & & BA & 9.32 & 189.55 & $<0.005$ \\
\hline Intercept + BA & $\mathrm{HI}$ & $\mathrm{RI}$ & 4.67 & 0.034 & $\mathrm{BA}$ & 8.70 & 149.45 & $<0.005$ \\
\hline
\end{tabular}

Models are arranged by increase of Akaike information criterion (AIC) and decrease of Akaike weight ( $w_{i}$ ). Models with $w_{i}<0.01$ are not shown. The probability associated to each fixed effect is also given; significant values are in bold. Abbreviations: $H S$ host species, $B A$ worm body area, $H I$ host individual, $R I$ random intercept, $R S$ random slope 

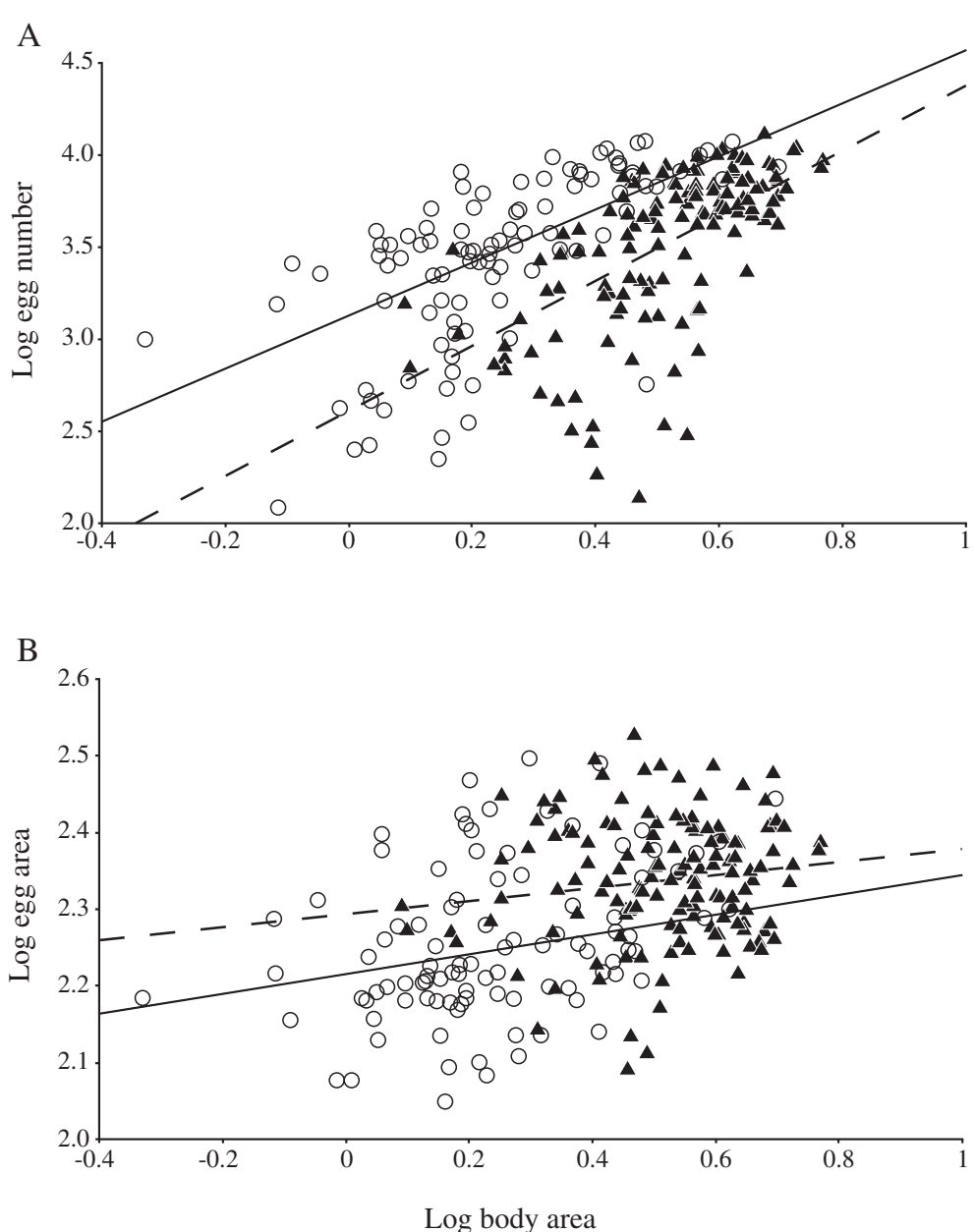

Fig. 2 Scatterplots showing the relationship of life-history traits in Pholeter gastrophilus. Scatterplots showing the relationship between $\log _{10}$-transformed values of (a) body area and number of eggs in utero and (b) body area and egg area of 237 individuals of the digenean Pholeter gastrophilus in five striped dolphins, Stenella coeruleoalba (triangles; $n=140$ ) and five bottlenose dolphins, Tursiops truncatus (circles; $n=97$ ) from the western Mediterranean. Regression lines were obtained from the best model that fit the data for striped dolphins (dashed line) and bottlenose dolphins (solid line)

(SE) was $-0.88(0.47)$; in the other four models values ranged from $-0.95(0.46)$ to $-0.82(0.48)$. 'Host species' and 'host species"egg area' were also selected in all five best supported models; apparently, the negative relationship between 'number of eggs' and 'egg area' was steeper in worms from striped dolphins (Fig. 3). However, 'host species', but not 'host species*egg area, was statistically significant (Table 5).

\section{Discussion}

Pholeter gastrophilus is considered a generalist species with a large range of hosts and a worldwide distribution. This raises the question as to whether this parasite might actually represent a complex of cryptic species [23], a phenomenon that has been observed in other digeneans, e.g. [55]. The lack of variation in the sequences of the LSU and ITS2 rDNA and mtCOI, respectively, suggests that individuals of $P$. gastrophilus collected from the striped and bottlenose dolphins are conspecific. Ribosomal genes exhibit some variable sites with phylogenetic information for congeneric taxa [13] whereas mitochondrial genes usually accumulate much higher nucleotide substitutions than rDNA, thus being especially useful for discriminating closely related species $[56,57]$. The absence of genetic differences in P. gastrophilus associated with host species could be related to the fact that striped and bottlenose dolphins utilise partially overlapping habitats [32] and share some preys in the study area $[58,59]$, thus enabling gene flow in the parasite population. Nevertheless, significant population structure might still occur in the neritic vs. oceanic populations of $P$. gastrophilus (see below). To detect intraspecific structure at this spatial scale, sequences of a much larger number of worms, and use of additional genetic markers are required (see, e.g. [60]). 
Table 4 General Linear Mixed Models with type III sum of squares accounting for the effect of host species (factor) and worm body area (covariate) on egg area of individuals of the digenean Pholeter gastrophilus collected from striped and bottlenose dolphins

\begin{tabular}{|c|c|c|c|c|c|c|c|c|}
\hline \multicolumn{3}{|l|}{ Model } & \multirow[t]{2}{*}{$\triangle \mathrm{AIC}$} & \multirow[t]{2}{*}{$w_{i}$} & \multirow[t]{2}{*}{ Predictor } & \multirow[t]{2}{*}{$\mathrm{t}$} & \multirow[t]{2}{*}{$\mathrm{df}$} & \multirow[t]{2}{*}{$p$} \\
\hline Fixed effects & Random effects & Covariance structure & & & & & & \\
\hline Intercept + BA & $\mathrm{HI}$ & $\mathrm{Rl}$ & 0 & 0.506 & $\mathrm{BA}$ & 3.66 & 165.54 & $<0.005$ \\
\hline Intercept + BA & $\mathrm{HI}+\mathrm{BA}$ & $\mathrm{RI}+\mathrm{RS}$ & 2.00 & 0.186 & BA & 3.66 & 165.53 & $<0.005$ \\
\hline \multirow[t]{2}{*}{ Intercept + HS + BA } & $\mathrm{HI}$ & $\mathrm{Rl}$ & 2.33 & 0.158 & $\mathrm{HS}$ & 1.58 & 10.05 & 0.145 \\
\hline & & & & & BA & 2.98 & 223.38 & $<0.005$ \\
\hline \multirow[t]{2}{*}{ Intercept + HS + BA } & $\mathrm{HI}+\mathrm{BA}$ & $\mathrm{RI}+\mathrm{RS}$ & 4.33 & 0.058 & $\mathrm{HS}$ & 1.58 & 10.04 & 0.145 \\
\hline & & & & & BA & 2.98 & 223.35 & $<0.005$ \\
\hline \multirow[t]{3}{*}{ Intercept $+\mathrm{HS}+\mathrm{BA}+\mathrm{HS}^{*} \mathrm{BA}$} & $\mathrm{HI}$ & $\mathrm{Rl}$ & 5.51 & 0.032 & $\mathrm{HS}$ & 1.40 & 23.44 & 0.175 \\
\hline & & & & & BA & 2.27 & 222.45 & 0.024 \\
\hline & & & & & $\mathrm{HS} * \mathrm{BA}$ & -0.23 & 222.45 & 0.820 \\
\hline Intercept + HS & $\mathrm{HI}$ & $\mathrm{RI}$ & 6.45 & 0.020 & HS & 2.74 & 8.28 & 0.025 \\
\hline
\end{tabular}

Models are arranged by increase of Akaike information criterion (AIC) and decrease of Akaike weight $\left(w_{i}\right)$. Models with $w_{i}<0.01$ are not shown. The probability associated to each fixed effect is also given; significant values are in bold. Abbreviations: $B A$ worm body area, $H I$ host individual, $R I$ random intercept, $R S$ random slope, HS host species

Infection levels of P. gastrophilus were similar in both striped and bottlenose dolphins; prevalence was virtually identical, and differences in worm intensity were not significant. To understand how the contact and/or compatibility filters generate this similarity, we would need information about (i) the diet of each dolphin species; (ii) the life cycle of P. gastrophilus; and (iii) the potential effect of hosts' physiological or immunological factors on mortality rates of parasites. The latter factor cannot be ascertained unless experimental infections are carried out. Concerning host-parasite contact, in the study area, striped dolphins feed primarily on oceanic mesopelagic fish and cephalopods [58], although they may consume some neritic fish, e.g. juvenile hake, Merluccius merluccius, or cephalopods, e.g. Illex coindetii [61]. In contrast, bottlenose dolphins feed largely on demersal neritic fish (especially hake) and, to a lesser extent, on benthic cephalopods [59]. Thus, it is puzzling how P. gastrophilus is able to infect a sizeable proportion of two dolphin species with such a small overlap in habitat and diet. The problem is compounded because, in the study area, this parasite also infects other oceanic cetaceans that feed almost exclusively on mesopelagic cephalopods [28, 29]. Unfortunately, parasitological surveys have failed to find infective stages of $P$. gastrophilus in the main prey of striped and bottlenose dolphins, see $[62,63]$. Based on data from other digeneans infecting pelagic vertebrates [64-66] we can postulate that $P$. gastrophilus extensively exploits the food web to reach its definitive hosts, but it is unclear to what extent the transmission routes are different depending on each cetacean species.

In parasitic platyhelminths, a large body size has been linked to a suite of life history traits including low mortality, long maturation time, slow growth rate and high reproductive output [35]. In P. gastrophilus, a larger body size was correlated with both a higher number of eggs in utero and larger eggs, similarly as in other digeneans, e.g. [67, 68]. Also, individuals of $P$. gastrophilus were able to mature and reproduce in both dolphin hosts, but worms were significantly larger in striped dolphins and also harboured larger eggs. These differences were consistent regardless of substantial variability associated to host individual, and did not appear to be confounded by differential density-dependence [5]. In fact, bottlenose dolphins provided a larger microhabitat (stomach area: $520 \mathrm{~cm}^{2}$ vs. $297 \mathrm{~cm}^{2}$ in striped dolphins, F.J. Aznar, unpub. obs.) but harboured smaller parasites that produced smaller eggs.

The larger investment in body size and egg size of $P$. gastrophilus in striped dolphins tentatively suggests that they are more suitable hosts than bottlenose dolphins. The absolute number of eggs in utero did not differ between hosts, but this measure of fecundity is just a 'snapshot' of the total egg output that a digenean can produce throughout its lifetime [69]. In digeneans, the adult size has a significant positive effect on the total reproductive output [35], thus we cannot rule out that worms from striped dolphins also have a higher overall fecundity. On the other hand, if bottlenose dolphins impose higher adult mortality rates of $P$. gastrophilus, shorter parasite maturation times and smaller body sizes should be favoured by natural selection (see [34]). This would explain why, for a given body size, worms from bottlenose dolphins had a relatively higher number of eggs in utero. Although the reasons for such contrasting host suitability are unknown, the possibility that differences in host's immune response play a role should not be underestimated, since infection with $P$. gastrophilus elicit a significant immune reaction associated to the formation of fibrotic nodules [70]. 
Table 5 General Linear Mixed Models with type I sum of squares accounting for the trade-off between egg number and egg area of individuals of Pholeter gastrophilus collected from striped and bottlenose dolphins, controlling for worm body area (covariate)

\begin{tabular}{|c|c|c|c|c|c|c|c|c|}
\hline \multicolumn{3}{|l|}{ Model } & \multirow[t]{2}{*}{$\triangle \mathrm{AlC}$} & \multirow[t]{2}{*}{$w_{i}$} & \multirow[t]{2}{*}{ Predictor } & \multirow[t]{2}{*}{$\mathrm{F}$} & \multirow[t]{2}{*}{$\mathrm{df}$} & \multirow[t]{2}{*}{$p$} \\
\hline Fixed effects & Random effects & Covariance structure & & & & & & \\
\hline \multirow[t]{5}{*}{ Intercept + BA + EA + HS + HS*BA + HS*EA } & $\mathrm{HI}$ & $\mathrm{Rl}$ & 0 & 0.231 & $\mathrm{BA}$ & 24.93 & $1,9.6$ & $<0.005$ \\
\hline & & & & & EA & 31.18 & $1,120.4$ & $<0.005$ \\
\hline & & & & & $\mathrm{HS}$ & 5.66 & $1,9.7$ & 0.040 \\
\hline & & & & & $H S^{*} B A$ & 0.27 & $1,195.8$ & 0.601 \\
\hline & & & & & $H S^{*} E A$ & 2.45 & $1,198.2$ & 0.119 \\
\hline \multirow[t]{4}{*}{ Intercept + BA + EA + HS + HS*EA } & $\mathrm{HI}$ & $\mathrm{Rl}$ & 0.36 & 0.193 & BA & 24.49 & $1,9.3$ & $<0.005$ \\
\hline & & & & & EA & 31.03 & $1,119.2$ & $<0.005$ \\
\hline & & & & & $\mathrm{HS}$ & 5.85 & $1,9.5$ & 0.037 \\
\hline & & & & & $H S^{*} E A$ & 1.99 & 1, 199.0 & 0.160 \\
\hline \multirow[t]{5}{*}{ Intercept $+\mathrm{BA}+\mathrm{EA}+\mathrm{HS}+\mathrm{HS}{ }^{*} \mathrm{BA}+\mathrm{HS}{ }^{*} \mathrm{EA}$} & $\mathrm{HI}+\mathrm{EA}$ & $\mathrm{Rl}+\mathrm{RS}$ & 1.66 & 0.101 & BA & 24.42 & $1,9.4$ & $<0.005$ \\
\hline & & & & & EA & 29.53 & $1,114.1$ & $<0.005$ \\
\hline & & & & & HS & 5.51 & $1,9.5$ & 0.042 \\
\hline & & & & & $H S^{*} B A$ & 0.19 & 1, 196.0 & 0.661 \\
\hline & & & & & $H S^{*} E A$ & 2.67 & 1, 192.1 & 0.104 \\
\hline \multirow[t]{4}{*}{ Intercept + BA + EA + HS + HS*EA } & $\mathrm{HI}+\mathrm{EA}$ & $R I+R S$ & 1.92 & 0.089 & BA & 24.09 & $1,9.2$ & $<0.005$ \\
\hline & & & & & EA & 29.35 & $1,113.0$ & $<0.005$ \\
\hline & & & & & $\mathrm{HS}$ & 5.70 & $1,9.4$ & 0.040 \\
\hline & & & & & $H S^{*} E A$ & 2.24 & $1,191.4$ & 0.136 \\
\hline \multirow[t]{5}{*}{ Intercept $+\mathrm{BA}+\mathrm{EA}+\mathrm{HS}+\mathrm{HS}^{*} \mathrm{BA}+\mathrm{HS} \mathrm{S}^{*} \mathrm{~A}$} & $\mathrm{HI}+\mathrm{BA}$ & $R I+R S$ & 2.00 & 0.085 & BA & 24.93 & $1,9.6$ & $<0.005$ \\
\hline & & & & & EA & 31.18 & $1,120.4$ & $<0.005$ \\
\hline & & & & & $\mathrm{HS}$ & 5.66 & $1,9.7$ & 0.040 \\
\hline & & & & & $\mathrm{HS} * \mathrm{BA}$ & 0.27 & $1,195.8$ & 0.601 \\
\hline & & & & & $H S^{*} E A$ & 2.45 & 1, 198.2 & 0.119 \\
\hline \multirow[t]{4}{*}{ Intercept $+\mathrm{BA}+\mathrm{EA}+\mathrm{HS}+\mathrm{HS}{ }^{*} \mathrm{EA}$} & $\mathrm{HI}+\mathrm{BA}$ & $\mathrm{RI}+\mathrm{RS}$ & 2.36 & 0.071 & BA & 24.49 & $1,9.3$ & $<0.005$ \\
\hline & & & & & EA & 31.03 & $1,119.2$ & $<0.005$ \\
\hline & & & & & $\mathrm{HS}$ & 5.85 & $1,9.5$ & 0.037 \\
\hline & & & & & $H S^{*} E A$ & 1.99 & 1, 199.0 & 0.160 \\
\hline \multirow[t]{3}{*}{ Intercept + BA + EA + HS } & $\mathrm{HI}$ & $\mathrm{Rl}$ & 3.00 & 0.052 & BA & 22.76 & $1,9.1$ & $<0.005$ \\
\hline & & & & & EA & 39.23 & $1,137.1$ & $<0.005$ \\
\hline & & & & & $\mathrm{HS}$ & 4.89 & $1,9.2$ & 0.054 \\
\hline \multirow[t]{4}{*}{ Intercept + BA + EA + HS + HS*BA } & $\mathrm{HI}$ & $\mathrm{Rl}$ & 3.14 & 0.048 & BA & 22.74 & $1,9.2$ & $<0.005$ \\
\hline & & & & & EA & 39.41 & $1,137.9$ & $<0.005$ \\
\hline & & & & & $\mathrm{HS}$ & 4.65 & $1,9.3$ & 0.058 \\
\hline & & & & & $H S^{*} B A$ & 0.30 & 1, 201.1 & 0.583 \\
\hline \multirow[t]{5}{*}{ Intercept $+\mathrm{BA}+\mathrm{EA}+\mathrm{HS}+\mathrm{HS}^{*} \mathrm{BA}+\mathrm{HS}^{*} \mathrm{EA}$} & $\mathrm{HI}+\mathrm{BA}+\mathrm{EA}$ & $\mathrm{RI}+\mathrm{RS}$ & 4.65 & 0.023 & BA & 27.79 & 1, 3133.1 & $<0.005$ \\
\hline & & & & & EA & 33.21 & $1,352.7$ & $<0.005$ \\
\hline & & & & & $\mathrm{HS}$ & 6.29 & 1, 3119.3 & 0.012 \\
\hline & & & & & $\mathrm{HS} * \mathrm{BA}$ & 0.27 & $1,323.9$ & 0.605 \\
\hline & & & & & $H S^{*} E A$ & 2.66 & 1, 298.4 & 0.104 \\
\hline
\end{tabular}


Table 5 General Linear Mixed Models with type I sum of squares accounting for the trade-off between egg number and egg area of individuals of Pholeter gastrophilus collected from striped and bottlenose dolphins, controlling for worm body area (covariate) (Continued)

\begin{tabular}{|c|c|c|c|c|c|c|c|c|}
\hline \multirow[t]{3}{*}{ Intercept $+\mathrm{BA}+\mathrm{EA}+\mathrm{HS}$} & \multirow[t]{3}{*}{$\mathrm{HI}+\mathrm{EA}$} & \multirow[t]{3}{*}{$\mathrm{Rl}+\mathrm{RS}$} & \multirow[t]{3}{*}{4.84} & \multirow[t]{3}{*}{0.021} & BA & 23.29 & $1,9.0$ & $<0.005$ \\
\hline & & & & & EA & 36.91 & $1,91.0$ & $<0.005$ \\
\hline & & & & & HS & 4.36 & $1,9.2$ & 0.066 \\
\hline
\end{tabular}

Models are arranged by increase of Akaike information criterion (AIC) and decrease of Akaike weight $\left(w_{i}\right)$. Models with $w_{i}<0.01$ are not shown. The probability associated to each fixed effect is also given; significant values are in bold. Abbreviations: $B A$ worm body area, EA egg area, $H S$ host species, $H I$ host individual, $R I$ random intercept, $R S$ random slope

According to the above discussion, individuals of $P$. gastrophilus seem to adopt different reproductive strategies depending on the host species, i.e. larger worms in the seemingly suitable hosts (striped dolphins) allocate resources for both somatic growth and production of large eggs, whereas smaller worms in the presumably suboptimal hosts (bottlenose dolphins) primarily allocate resources for egg production. The reasons why the absolute number of eggs in utero was not significantly higher in worms from striped dolphins deserve further attention. Perhaps there are spatial constraints on the amount of eggs that the uterus can harbour [71], so the larger body size (= uterus) in worms from striped dolphins would be inconsequential for harbouring more eggs if eggs are also larger. A second, non-exclusive hypothesis is that a trade-off could exist between egg size and egg number so that worms in striped dolphins produce larger eggs at the expense of lowering fecundity (see [72, 73]). In fact, we obtained evidence of such trade-off, not only in striped dolphins, but also in bottlenose dolphins. This would empirically confirm that parasites could not equally invest into both quantity and quality of offspring $[74,75]$. Apparently, individuals of $P$. gastrophilus are at their maximum reproductive capacity (see [76]), thus the higher allocation in egg size observed in worms from striped dolphins should involve higher costs for egg production. In support of this, the slope of the egg size-egg number regression, corrected for body size, seemed to be steeper in worms from striped dolphins, and indeed the best models examining the trade-off included the interaction between host species and egg area. However, this interaction was not statistically significant, which suggest that a great deal of unexplained variability also exist among individual hosts.

The previous discussion raises the question as to why adults of P. gastrophilus in the most suitable host opt to produce larger eggs rather than more numerous but smaller eggs. A possible explanation is that in an aquatic environment, the offspring can potentially be exposed to elevated levels of mortality (see, e.g. [19, 20, 77]). In particular, the first infective stage (which, depending on the putative life-cycle of $P$. gastrophilus, could be the egg, or the free-living miracidium that emerges from the egg) must face the challenge to contact the first intermediate host, and subsequent infective stages must make their way through the trophic web to infect a top predator. As noted above, Mediterranean striped and bottlenose dolphins favour different habitats, namely, oceanic vs. neritic [32, 78], which could pose different selective pressures. Oceanic ecosystems are widely recognised as

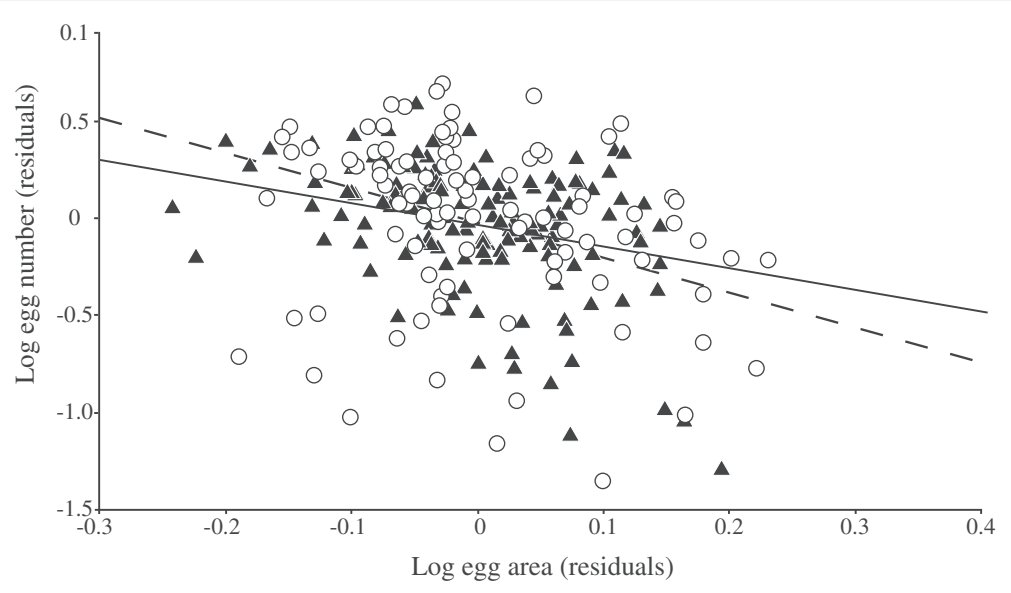

Fig. 3 Scatterplot showing the relationship between body-size corrected residuals of egg area and number of eggs in utero of the digenean Pholeter gastrophilus in striped dolphins, Stenella coeruleoalba (triangles) and bottlenose dolphins, Tursiops truncatus (circles) from the western Mediterranean. Regression lines were obtained from the best model that fit the data for striped dolphins (dashed line) and bottlenose dolphins (solid line) 
having significantly lower levels of productivity than neritic ones [79], which also results in much lower density of organisms [64, 80]. From the perspective of P. gastrophilus, the oceanic habitat would therefore be much more adverse for transmission. The production of large eggs would therefore be an adaptive response because large eggs generate large, long-lived miracidia [35, 81], thus enhancing the likelihood of finding the first intermediate host (see [82]). In addition, the potential to multiply asexually within the first intermediate host could also be proportional to larval size [73], which would increase further transmission opportunities in the most adverse environment. Interestingly, a similar phenomenon has been reported in the case of the digenean Proctoeces lintoni Siddiqui and Cable, 1960: compared with pristine areas, parasite individuals from human-disturbed areas exhibited larger eggs because harvesting by humans had reduced the density of intermediate and definitive hosts [20]. Assuming that differences in the reproductive traits of $P$. gastrophilus in each dolphin species are adaptive, they could result from two potential processes, i.e. (i) phenotypic plasticity, so that the reproductive strategy of $P$. gastrophilus could vary according to the cues emanated from the definitive host (see [20]), or (ii) local adaptation by natural selection, so that differences in reproductive allocation between coastal vs. oceanic populations of $P$. gastrophilus could have at least a partial genetic component. The operation of these two processes should be explored in future studies.

\section{Conclusions}

In summary, the results from the present study suggest that the reproductive strategy of $P$. gastrophilus could be differently optimised depending on the suitability of the host species and the local habitat where the life-cycle develops. As far as we are aware, this is the first study to document subtle differences in the reproductive strategy of a generalist helminth from marine mammals, illustrating how constraints and natural selection shape life history traits. Future research should explore whether differences between neritic and oceanic habitats have similar impact on the life-cycles of other trophicallytransmitted helminths.

\section{Competing interests}

The authors declare that they have no competing interests.

\section{Authors' contributions}

FJA and NFF conceived and participated in the study design, its coordination, and performed statistical analyses. NFF carried out the molecular studies. FJA, MF, JAR contributed with reagents/materials/analysis tools. NFF, FJA, MF, JAR drafted the manuscript. All authors read and approved the final manuscript.

\section{Acknowledgements}

We kindly thank personnel of the Marine Zoology Unit of the Cavanilles Institute of Biodiversity and Evolutionary Biology from the University of Valencia, especially Paola Fognani, for helping with the processing of the stranded dolphins. Special thanks to Drs Francisco E. Montero and Isabel Blasco-Costa for assistance on image processing and molecular work, respectively. Comments by two anonymous referees significantly improved the manuscript. Sequencing was made by the Central Services for Experimental Research from the University of Valencia (Spain). This study was supported by projects CGL/2012/39545 and CGL/2009/07465 (Ministry of Economy and Competitiveness, Spain), and PROMETEO II/2015/018 (Generalitat Valenciana, Spain).

Received: 30 October 2015 Accepted: 16 December 2015

Published online: 23 December 2015

\section{References}

1. Poulin R, Krasnov BR, Mouillot D. Host specificity in phylogenetic and geographic space. Trends Parasitol. 2011;27:355-61.

2. Combes $C$. The ecology and evolution of intimate interactions. Chicago: Chicago University Press; 2001.

3. Kuris AM, Goddard JHR, Torchin ME, Murphy N, Gurney R, Lafferty KD. An experimental evaluation of host specificity: the role of encounter and compatibility filters for a rhizocephalan parasite of crabs. Int J Parasitol. 2007:37:539-45.

4. Lane B, Spier T, Wiederholt J, Meagher S. Host specificity of a parasitic fluke: Is Posthodiplostomum minimum a centrarchid-infecting generalist or specialist? J Parasitol. 2015;101:6-17.

5. Beck MA, Goater CP, Colwell DD. Comparative recruitment, morphology and reproduction of a generalist trematode, Dicrocoelium dendriticum, in three species of host. Parasitology. 2015;142:1297-305.

6. Adams AM, Hoberg EP, McAlpine DF, Clayden SL. Occurrence and morphological comparisons of Campula oblonga (Digenea: Campulidae), including a report from an atypical host, the thresher shark, Alopias vulpinus. J Parasitol. 1998:84:435-8.

7. Perdiguero-Alonso D, Montero FE, Raga JA, Balbuena JA. Diclidophora merlangi (Monogenea: Diclidophoridae) on Atlantic cod, Gadus morhua. J Parasitol. 2006;92:697-702.

8. Mateu P, Raga JA, Aznar FJ. Host specificity of Oschmarinella rochebruni and Brachycladium atlanticum (Digenea: Brachycladiidae) in five cetacean species from western Mediterranean waters. J Helminthol. 2011;85:12-9.

9. George-Nascimento MA, Marin SL. Efecto de dos especies hospedadoras, el lobo fino austral Arctocephalus australis (Zimmerman) y el lobo marino común Otaria byronia (Blainville) (Carnivora; Otariidae), sobre la morfología y la fecundidad de Corynosoma sp. (Acanthocephala; Polymorphidae) en Uruguay. Rev Chil Hist Nat. 1992;65:183-93.

10. Riquelme C, George-Nascimento M, Balboa L. Morfometría y fecundidad de Profilicollis bullocki Mateo, Córdova \& Guzmán 1982 (Acanthocephala: Polymorphidae) en especies simpátricas de aves costeras de Chile. Rev Chil Hist Nat. 2006;79:465-74

11. Lootvoet A, Blanchet S, Gevrey M, Buisson L, Tudesque L, Loot G. Patterns and processes of alternative host use in a generalist parasite: insights from a natural host-parasite interaction. Funct Ecol. 2013;27:1403-14.

12. Jousson O, Bartoli P, Pawlowski J. Cryptic speciation among intestinal parasites (Trematoda: Digenea) infecting sympatric host fishes (Sparidae). J Evol Biol. 2000;13:778-85.

13. Blasco-Costa I, Balbuena JA, Raga JA, Kostadinova A, Olson PD. Molecules and morphology reveal cryptic variation among digeneans infecting sympatric mullets in the Mediterranean. Parasitology. 2010;137:287-302.

14. Krasnov BR, Sarfarti M, Arakelyan MS, Khokhlova IS, Burdelova NV, Degen AA Host specificity and foraging efficiency in blood-sucking parasite: feeding patterns of the flea Parapulex chephrenis on two species of desert rodents. Parasitol Res. 2003;90:393-9.

15. Beck MA, Goater CP, Colwell DD, Van Paridon BJ. Fluke abundance versus host age for an invasive trematode (Dicrocoelium dendriticum) of sympatric elk and beef cattle in southeastern Alberta, Canada. Int J Parasitol Parasites Wildl. 2014;3:263-8.

16. Sorci G, Skarstein F, Morand S, Hugot JP. Correlated evolution between host immunity and parasite life histories in primates and oxyurid parasites. Proc $R$ Soc B. 2003;270:2481-4.

17. Krasnov BR, Shenbrot Gl, Khokhlova IS, Poulin R. Relationships between parasite abundance and the taxonomic distance among a parasite's host species: an example with fleas parasitic on small mammals. Int J Parasitol. 2004;34:1289-97. 
18. Stearns SC. The evolution of life histories. New York, USA: Oxford University Press; 1992.

19. Poulin R, Hamilton WJ. Egg size variation as a function of environmental variability in parasitic nematodes. Can J Zool. 2000;78:564-9.

20. Loot G, Blanchet S, Aldana M, Navarrete SA. Evidence of plasticity in the reproduction of a trematode parasite: the effect of host removal. J Parasitol. 2008;94:23-7.

21. Koehler AV, Gonchar AG, Poulin R. Genetic and environmental determinants of host use in the trematode Maritrema novaezealandensis (Microphallidae). Parasitology. 2011;138:100-6.

22. Fraija-Fernández N, Olson PD, Crespo EA, Raga JA, Aznar FJ, Fernández M. Independent host switching events by digenean parasites of cetaceans inferred from ribosomal DNA. Int J Parasitol. 2015;45:167-73.

23. Aznar FJ, Fognani P, Balbuena JA, Pietrobelli M, Raga JA. Distribution of Pholeter gastrophilus (Digenea) within the stomach of four odontocete species: The role of the diet and digestive physiology of hosts. Parasitology. 2006:133:369-80

24. Migaki G, Van Dyke D, Hubbard RC. Some histopathological lesions caused by helminths in marine mammals. J Wildl Dis. 1971;7:281-9.

25. Gibson DI, Harris EA, Bray RA, Jepson PD, Kuiken T, Baker JR, et al. A survey of the helminth parasites of cetaceans stranded on the coast of England and Wales during the period 1990-1994. J Zool Lond. 1998;244:563-74.

26. Raga JA, Carbonell E, Raduán A, Blanco C. Sobre la presencia de Pholeter gastrophilus (Kossack, 1910) (Trematoda: Troglotrematidae), en quistes estomacales de Tursiops truncatus y Stenella coeruleoalba (Cetacea: Delphinidae), en las costas españolas del Mediterráneo. Rev Ibér Parasitol. 1985:45:123-8.

27. Raga JA, Balbuena JA. Algunas características zoogeográficas de los helmintos de los cetáceos en el Mediterráneo con especial referencia a la helmintofauna del delfín listado. In: Sans-Coma V, Mas-Coma S, Gosálbez J, editors. Mamíferos y helmintos. Barcelona: Ketres Editora; 1987. p. 195-201.

28. Raga JA, Balbuena JA. Parasites of the long-finned pilot whale Globicephala melas (Trail, 1809) in European waters. Rep Int Whal Commn. 1993:14:391-406.

29. Fernández M, Agustí C, Aznar FJ, Raga JA. Gastrointestinal helminths of Risso's dolphin Grampus griseus from the Western Mediterranean. Dis Aquat Org. 2003;55:73-6.

30. Quiñones R, Giovannini A, Raga JA, Fernández M. Intestinal helminth fauna of bottlenose dolphins Tursiops truncatus and common dolphin Delphinus delphis from the Western Mediterranean. J Parasitol. 2013:99:576-9.

31. Cañadas A, Sagarminaga R. The Northeastern Alboran Sea, an important breeding and feeding ground for the long-finned pilot whale (Globicephala melas) in the Mediterranean Sea. Mar Mamm Sci. 2000;16:513-29.

32. Gómez de Segura A, Hammond PS, Raga JA. Influence of environmental factor on small cetacean distribution in the Spanish Mediterranean. J Mar Biol Assoc UK. 2008;88:1185-92

33. Poulin R. Clutch size and egg size in free-living and parasitic copepods: a comparative analysis. Evolution. 1995;49:325-36.

34. Morand S, Sorci G. Determinants of life-history evolution in nematodes. Parasitol Today. 1998;14:193-6.

35. Trouvé S, Sasal P, Jourdane J, Renaud F, Morand S. The evolution of life-history traits in parasitic and free-living platyhelminthes: a new perspective. Oecologia. 1998;115:370-8.

36. Geraci JR, Lounsbury VJ. Marine mammals ashore: a field guide for strandings. Baltimore: National Aquarium; 2005.

37. Littlewood DTJ, Johnston DA. Molecular phylogenetics of the four Schistosoma species groups determined with partial $28 \mathrm{~S}$ ribosomal RNA gene sequences. Parasitology. 1995;111:167-75.

38. Olson PD, Cribb TH, Tkach W, Bray RA, Littlewood DTJ. Phylogeny and classification of the Digenea (Platyhelminthes: Trematoda). Int J Parasitol. 2003:33:733-5.

39. Morgan JAT, Blair D. Nuclear rDNA ITS sequence variation in the trematode genus Echinostoma: an aid to establishing relationships within the 37-collarspine group. Parasitology. 1995;111:609-15.

40. Anderson GR, Barker SC. Inference of phylogeny and taxonomy within the Didymozoidae (Digenea) from the second internal transcribed spacer (ITS2) of ribosomal DNA. Syst Parasitol. 1998;41:87-94.

41. Morgan JAT, Blair D. Relative merits of nuclear ribosomal internal transcribed spacers and mitochondrial CO1 and ND1 genes for distinguishing among Echinostoma species (Trematoda). Parasitology. 1998;116:289-97.
42. Razo-Mendivil U, Rosas-Valdez R, Pérez-Ponce de León G. A new cryptogonimid (Digenea) from the mayan cichlid, Cichlasoma urophthalmus (Osteichthyes: Cichlidae), in several localities of the Yucatán Peninsula, México. J Parasitol. 2008:94:1371-8.

43. Littlewood DTJ, Curini-Galletti M, Herniou EA. The interrelationships of Proseriata (Platyhelminthes: Seriata) tested with molecules and morphology. Mol Phylogenet Evol. 2000;16:449-66.

44. Hall TA. Bioedit: a user-friendly biological sequence editor and analysis program for windows 95/98/NT. Nucleic Acids Symp Ser. 1999;41:95-8.

45. Reiczigel J. Confidence intervals for the binomial parameter: some new considerations. Stat Med. 2003;22:611-21.

46. Rózsa L, Reiczigel J, Majoros G. Quantifying parasites in samples of hosts. J Parasitol. 2000:86:228-32.

47. Neuhäuser M, Poulin R. Comparing parasite numbers between samples of hosts. J Parasitol. 2004;90:689-91.

48. Lefebvre F, Poulin R. Alternative reproductive strategies in the progenetic trematode Coitocaecum parvum: Comparison of selfing and mating worms. J Parasitol. 2005;91:93-8.

49. Valero MA, de Renzi M, Panova M, García-Bodelon MA, Periago MV, Ordoñez $D$, et al. Crowding effect on adult growth, pre-patent period and egg shedding of Fasciola hepatica. Parasitology. 2006;133:453-63.

50. Wilcox CD, Dove SB, McDavid WD, Greer DB. ImageTool, University of Texas Health Science Centre at San Antonio. http://compdent.uthscsa.edu/dig/ download.html. Accessed 28 October 2015

51. Singer JD, Using SAS. PROC MIXED to fit multilevel models, hierarchical models, and individual growth models. J Educ Behav Stats. 1998;24:323-55.

52. Johnson JB, Omland KS. Model selection in ecology and evolution. Trends Ecol Evol. 2004;19:101-8.

53. Burnham KP, Anderson DR. Model selection and multimodel inference. A practical information-theoretic approach. New York: Springer; 2002.

54. Hector A, Von Felten S, Schmid B. Analysis of variance with unbalanced data: an update for ecology and evolution. J Anim Ecol. 2010;79:308-16.

55. Georgieva S, Faltynková A, Brown R, Blasco-Costa I, Soldánová M, Sitko J, et al. Echinostoma 'revolutum' (Digenea: Echinostomatidae) species complex revisited: species delimitation based on novel molecular and morphological data gathered in Europe. Parasit Vectors. 2014;7:520.

56. Vilas R, Criscione CD, Blouin MS. A comparison between mitochondrial DNA and the ribosomal internal transcribed regions in prospecting for cryptic species of platyhelminth parasites. Parasitology. 2005;131:839-46.

57. Perkins SL, Martinsen ES, Falk BG. Do molecules matter more than morphology? Promises and pitfalls in parasites. Parasitology. 2011;138:1664-74.

58. Blanco C, Aznar FJ, Raga JA. Cephalopods in the diet of the striped dolphin Stenella coeruleoalba from the western Mediterranean during an epizootic in 1990. J Zool Lond. 1995;237:151-8

59. Blanco C, Salomón O, Raga JA. Diet of the bottlenose dolphin (Tursiops truncatus) in the western Mediterranean Sea. J Mar Biol Ass UK. 2001:81:1053-8.

60. Blasco-Costa I, Waters JM, Poulin R. Swimming against the current: genetic structure, host mobility and the drift paradox in trematode parasites. Mol Ecol. 2012;21:207-17.

61. Aznar FJ, Míguez-Lozano R, Bosch de Castro A, Ruiz B, Raga JA, Blanco C. Long-term changes in the diet of striped dolphins, Stenella coeruleoalba, in the western Mediterranean: a comparison of stomach contents vs. stable isotopes. In: Proceedings of the $29^{\text {th }}$ Conference of the European Cetacean Society. Malta: St. Julian's Bay; 2015.

62. Ferrer-Maza D, Lloret J, Muñoz M, Faliex E, Vila S, Sasal P. Parasitism, condition and reproduction of the European hake (Merluccius merluccius) in the northwestern Mediterranean Sea. ICES J Mar Sci. 2014;71:1088-99.

63. Mateu P, Nardi V, Fraija-Fernández N, Mattiucci S, Gil De Sola L, Raga JA, et al. The role of lantern fish (Myctophidae) in the life-cycle of cetacean parasites from western Mediterranean waters. Deep Sea Res Part 1. 2015:95:115-21.

64. Marcogliese DJ. The role of zooplankton in the transmission of helminth parasite to fish. Rev Fish Biol Fish. 1995:5:336-71.

65. Daponte MC, Gil de Pertierra AA, Palmieri MA, Ostrowski de Nuñez M. Monthly occurrence of parasites of the chaetognath Sagitta friderici off Mar del Plata, Argentina. J Plankton Res. 2006;30:567-76.

66. Diaz Briz LM, Martorelli SR, Genzano GN, Mianzan HW. Parasitism (Trematoda, Digenea) in medusae from the southwestern Atlantic Ocean: medusa hosts, parasite prevalences, and ecological implications. Hydrobiologia. 2012;690:215-26. 
67. Oliva ME, Alvarez C. Is a vertebrate a better host for a parasite than an invertebrate host? Fecundity of Proctoeces cf. lintoni (Digenea: Fellodistomidae), a parasite of fish and gastropods in northern Chile. Parasitol Res. 2011:109:1731-4.

68. González MT, Henríquez V, López Z. Variations in the fecundity and body size of digenean (Opecoelidae) species parasitizing fishes from Northern Chile. Rev Biol Mar Oceanog. 2013;48:421-9.

69. Whittington ID. Reproduction and host-location among the parasitic Platyhelminthes. Int J Parasitol. 1997;27:705-14.

70. Howard EB, Britt JO, Matsumoto G. Parasitic diseases. In: Howard EB, editor. Pathobiology of marine mammal diseases. Boca Raton: CRC Press; 1983. p. 119-232.

71. Herreras MV, Montero FE, Marcogliese DJ, Raga JA, Balbuena JA. Phenotypic tradeoffs between egg number and egg size in three parasitic anisakid nematodes. Oikos. 2007:116:1737-47.

72. Poulin R. The evolution of life history strategies in parasitic animals. Adv Parasitol. 1996;37:107-34.

73. Poulin R. Egg production in adult trematodes: adaptation or constraint? Parasitology. 1997;114:195-204.

74. Jennings JB, Calow P. The relationship between high fecundity and the evolution of entoparasitism. Oecologia. 1975;21:109-15.

75. Poulin R. Evolution of life history traits: myths and reality. Parasitol Today. 1995;11:342-54

76. Cavaleiro Fl, Santos MJ. Egg number-egg size: An important trade-off in parasite life history strategies. Int J Parasitol. 2014;44:173-82.

77. Loot G, Poulet N, Brosse S, Tudesque L, Thomas F, Blanchet S. Determinants of life-history traits in a fish ectoparasite: a hierarchical analysis. Parasitology. 2011;138:848-57.

78. Forcada J, Gazo M, Aguilar A, Gonzalvo J, Fernández-Contreras M. Bottlenose dolphin abundance in the NW Mediterranean: addressing heterogeneity in distribution. Mar Ecol Prog Ser. 2004;275:275-87.

79. Moore SE. Long-term environmental change and marine mammals. In: Reynolds JE, Perrin WF, Reeves RR, Montgomery S, Ragen TJ, editors. Marine mammal research. Conservation beyond crisis. Maryland: The Johns Hopkins University Press; 2005. p. 137-48.

80. Huston MA. Biological diversity, The coexistence of species on changing landscapes. Cambridge: Cambridge University Press; 1998.

81. Morand S. Life-history traits in parasitic nematodes: a comparative approach for the search of invariants. Funct Ecol. 1996;10:210-8.

82. Koehler AV, Brown B, Poulin R, Thieltges DW, Fredensborg P. Disentangling phylogenetic constraints from selective forces in the evolution of trematode transmission stages. Evol Ecol. 2012;26:1497-512.

\section{Submit your next manuscript to BioMed Central and we will help you at every step:}

- We accept pre-submission inquiries

- Our selector tool helps you to find the most relevant journal

- We provide round the clock customer support

- Convenient online submission

- Thorough peer review

- Inclusion in PubMed and all major indexing services

- Maximum visibility for your research

Submit your manuscript at www.biomedcentral.com/submit 